\title{
Head or Neck First? Speed and Rates of Reperfusion in Thrombectomy for Tandem Large Vessel Occlusion Strokes
}

\author{
Diogo C. Haussen ${ }^{a} \quad$ Francis Turjman ${ }^{b}$ Michel Piotin ${ }^{c} \quad$ Julien Labreuche ${ }^{d}$ \\ Henrik Steglich-Arnholm ${ }^{e}$ Markus Holtmannspötter ${ }^{f}$ Christian Taschnerg \\ Sebastian Eiden ${ }^{9}$ Raul G. Nogueira ${ }^{a}$ Panagiotis Papanagiotou ${ }^{\text {h }}$ Maria Boutchakova $^{\text {h }}$ \\ Adnan H. Siddiqui ${ }^{i}$ Bertrand Lapergue ${ }^{j}$ Franziska Dornk ${ }^{k}$ Christophe Cognard ${ }^{\prime}$ \\ Monika Killer $^{m}$ Salvatore Mangiafico ${ }^{n}$ Marc Ribo $^{\circ}$ Marios N. Psychogios ${ }^{p}$ \\ Alejandro M. Spiotta $q$ Marc-Antoine Labeyrie ${ }^{r}$ Mikael Mazighic, v, w \\ Alessandra Biondis Sébastien Richard ${ }^{\text {t, } u}$ Jonathan A. Grossberg ${ }^{a}$ \\ René Anxionnat ${ }^{x, y}$ Serge Bracard ${ }^{x, y}$ Benjamin Gory ${ }^{x, y}$ \\ on behalf of the TITAN (Thrombectomy In TANdem Lesions) Investigators
}

aDepartment of Neurology, Emory University/Grady Memorial Hospital, Atlanta, GA, USA; ${ }^{b}$ Department of Interventional Neuroradiology, Hospices Civils, Lyon, France; ${ }^{c}$ Department of Interventional Neuroradiology, Hôpital de la Fondation Ophtalmologique Adolphe de Rothschild, Paris, France; ${ }^{d}$ Department of Biostatistics, University of Lille, CHU Lille, EA 2694-Santé Publique: Épidémiologie et Qualité des Soins, Lille, France; ${ }^{e}$ Department of Neurology, Rigshospitalet, Copenhagen, Denmark; ${ }^{f}$ Department of Neuroradiology, Rigshospitalet, Copenhagen, Denmark; ${ }^{9}$ Department of Neuroradiology, Medical Center, University of Freiburg, Freiburg, Germany; hDiagnostic and Interventional Neuroradiology, Hospital Bremen-Mitte/Bremen-Ost, Bremen, Germany; 'Department of Neurosurgery, State University of New York, Buffalo, NY, USA; jDepartment of Neurology, Stroke Center, Foch Hospital, Suresnes, France; ${ }^{k}$ Department of Neuroradiology, University Hospital of Munich, Munich, Germany; 'Department of Neuroradiology, University Hospital of Toulouse, Toulouse, France; ${ }^{m}$ Department of Neuroradiology, Paracelsus Medical University Salzburg, Salzburg, Austria; ${ }^{\mathrm{n}}$ Department of Interventional Neuroradiology, Careggi University Hospital, Florence, Italy; ${ }^{\circ}$ Department of Neurology, Hospital Vall D’Hebron, Barcelona, Spain; ${ }^{\mathrm{P}}$ Department of Neuroradiology, University Medical Center Göttingen, Göttingen, Germany; ${ }^{9}$ Department of Neurosurgery, Medical University of South Carolina, Charleston, SC, USA; ' Department of Interventional Neuroradiology, Lariboisière Hospital, Paris, France; ${ }^{s}$ Department of Neuroradiology and Endovascular Therapeutic, University Hospital of Besançon, Besançon, France; 't Stroke Unit, Department of Neurology, University Hospital of Nancy, Nancy, France; "Centre d'Investigation Clinique Plurithématique, INSERM U1116, Nancy,

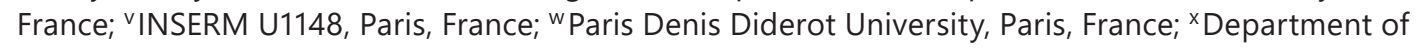
Diagnostic and Therapeutic Neuroradiology, University Hospital of Nancy, Nancy, France; y University of Lorraine, INSERM U1254, Nancy, France

A list of TITAN (Thrombectomy In TANdem Lesions) investigators is given in the Appendix.

Benjamin Gory, MD, PhD

29 Avenue du Maréchal de Lattre de Tassigny

FR-54035 Nancy (France)

E-Mail b.gory@chru-nancy.fr
Diogo C. Haussen, MD

80 Jesse Hill Jr. Drive SE, Box 036

Atlanta, GA 30303 (USA)

E-Mail diogo.haussen@emory.edu 


\title{
Keywords
}

Carotid artery $\cdot$ Thrombectomy $\cdot$ Stroke

\begin{abstract}
Background: We aim to evaluate the speed and rates of reperfusion in tandem large vessel occlusion acute stroke patients undergoing upfront cervical lesion treatment (Neck-First: angioplasty and/or stent before thrombectomy) as compared to direct intracranial occlusion therapy (Head-First) in a large international multicenter cohort. Methods: The Thrombectomy In TANdem Lesions (TITAN) collaboration pooled individual data of prospectively collected thrombectomy international databases for all consecutive anterior circulation tandem patients who underwent emergent thrombectomy. The co-primary outcome measures were rates of successful reperfusion (modified Thrombolysis in Cerebral Infarction 2b/3) and time from groin puncture to successful reperfusion. Results: In total, 289 patients with tandem atherosclerotic etiology were included in the analysis (182 Neck-First and 107 Head-First patients). Except for differences in the Alberta Stroke Program Early CT Score (ASPECTS; median 8 [range 7-10] Neck-First vs. 7 [range 6-8] Head-First; $p<0.001$ ) and cervical internal carotid artery (ICA) lesion severity (complete occlusion in $35 \%$ of the Neck-First vs. $57 \%$ of the HeadFirst patients; $p<0.001$ ), patient characteristics were well balanced. After adjustments, there was no difference in successful reperfusion rates between the study groups (odds ratio associated with Neck-First: 1.18 [95\% confidence interval, 0.60-2.17]). The time to successful reperfusion from groin puncture was significantly shorter in the Head-First group after adjustments (median 56 min [range 39-90] vs. 70 [range 50-102]; $p=0.001$ ). No significant differences in the rates of full reperfusion, symptomatic hemorrhage, 90 -day independence, or mortality were observed. Sensitivity analysis excluding patients with complete cervical ICA occlusion yielded similar results. Conclusions: The upfront approach of the intracranial lesion in patients with tandem large vessel occlusion strokes leads to similar reperfusion rates but faster reperfusion as compared to initial cervical revascularization followed by mechanical thrombectomy. Controlled studies are warranted.

(C) 2019 S. Karger AG, Base
\end{abstract}

\section{Introduction}

The treatment effect of mechanical thrombectomy in patients with and without tandem extracranial steno-occlusive disease in large vessel occlusion acute ischemic stroke (LVOS) is comparable [1]. Considering the common occurrence of tandem occlusions in patients with LVOS treated with thrombectomy, refinements in procedural techniques related to these lesions are timely [2-4]. The cervical lesion in atherosclerotic tandem LVOS may be approached with angioplasty/stent prior to mechanical thrombectomy, or directly transversed for upfront intracranial treatment. The potential benefits and disadvantages of each approach have been presented in small patient series with conflicting results $[5,6]$. We aim to evaluate the speed and rates of reperfusion in tandem LVOS patients treated with head versus neck first approach in a large international multicenter cohort.

\section{Methods}

The Thrombectomy In TANdem Lesions (TITAN) collaboration pooled individual data of prospectively collected thrombectomy databases across 18 institutions for all consecutive anterior circulation tandem patients who underwent emergent thrombectomy between January 2012 and September 2016. Patient eligibility and methods of TITAN collaboration have been previously reported $[7,8]$. Patients were included in 
the present study, if there was an association of a large vessel intracranial occlusion (intracranial internal carotid or middle cerebral artery M1/M2) and an atherosclerotic cervical internal carotid artery (ICA) lesion (complete occlusion or stenosis $\geq 90 \%$ by NASCET criteria on baseline catheter-angiography angiogram). All patients were treated with modern mechanical devices (stent retrievers and/or large-bore distal aspiration catheters). Angiographic outcomes were self-reported. The sample was dichotomized in two groups according to the procedural approach: (1) neck lesion treated with angioplasty and/or stenting before cerebral thrombectomy (Neck-First), and (2) cerebral thrombectomy performed upfront (Head-First) followed by a decision regarding the cervical lesion (angioplasty and/or stenting or medical therapy alone without extracranial intervention).

Outcomes

The co-primary outcome measures were the (1) rate of successful reperfusion (defined as modified Thrombolysis in Cerebral Infarction [mTICI] scores 2b/3) and (2) time from groin puncture to successful intracranial reperfusion. Secondary outcomes included complete reperfusion (mTICI 3), favorable outcome (90-day modified Rankin Scale of 0-2), all-cause mortality at 90-days, any procedure-related complications, any intracranial hemorrhage (ICH), parenchymal hematoma, and symptomatic ICH. Symptomatic ICH was defined as any parenchymal hematoma, subarachnoid hemorrhage, or intraventricular hemorrhage associated with worsening of the National Institutes of Health Stroke Scale (NIHSS) score by 4 points or more.

\section{Statistical Analysis}

Continuous variables are expressed as mean \pm standard deviation or median (interquartile range), and categorical variables are expressed as numbers (percentage). Normality of distributions was assessed using histograms and the Shapiro-Wilk test. Main baseline characteristics were compared between the two study groups using the $\chi^{2}$ test or Fisher's exact test for categorical variables and the Student $t$ test or Mann-Whitney $\mathrm{U}$ test. We further calculated absolute standardized differences (ASD) to evaluate baseline imbalance; ASD $>20 \%$ were interpreted as meaningful imbalance. Binary outcomes were compared between the two study groups using a mixed logistic regression model including center as random effect; odds ratios (OR) were derived from this model as effect sizes using Head-First group as reference. Time from puncture to successful reperfusion (mTICI 2b/3) was compared between the two study groups using a linear mixed model on logtransformed values and including center as random effect. Comparisons in outcomes were further adjusted for baseline differences (ASD $>20 \%$ ) (namely fully-adjusted analysis). To avoid case deletion in multivariate analyses due to missing data, missing values were handling by multiple imputation using regression switching approach (chained equations with $m=10$ obtained using the R statistical software version 3.03) [9]. Imputation procedure was performed under the missing-at-random assumption using all baseline characteristics, and the study outcomes with a predictive mean-matching method for continuous variables and logistic regression models (binary, ordinal, or multinomial) for categorical variables. Estimates obtained in the different imputed data sets were combined using Rubin's rules [10]. Sensitivity analysis was performed after excluding patients with complete occlusion in cervical ICA to acknowledge the large between-group difference. Statistical testing was done at the two-tailed $\alpha$ level of 0.05. Data were analyzed using the SAS software version 9.4 (SAS Institute, Cary, NC, USA).

\section{Results}

Of 405 screened patients with tandem lesions, 81 patients with carotid dissection etiology, 28 with cardioembolic etiology, and 7 with undetermined etiology were excluded, yielding 289 patients with tandem atherosclerotic etiology included in the present analysis: 182 patients in the Neck-First vs. 107 in the Head-First group (Fig. 1).

Patient characteristics are shown for the overall study population and according to the study groups in Table 1. Except for significant differences in ischemic core (median Alberta Stroke Program Early CT Score, ASPECTS; 8 [7-10] Neck-First vs. 7 [6-8] Head-First; $p<$ 0.001 ) and cervical ICA lesion severity (complete cervical ICA occlusion in 35\% of Neck-First vs. $57 \%$ of Head-First; $p<0.001$ ), patient characteristics were well balanced. 


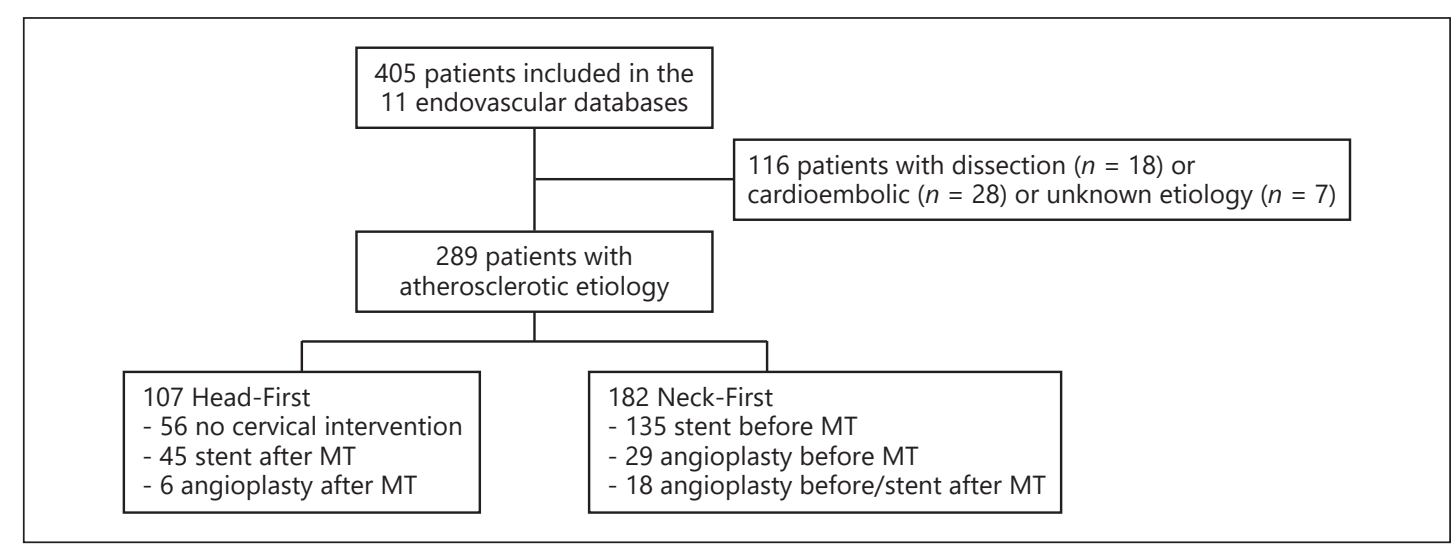

Fig. 1. Flow diagram. MT, mechanical thrombectomy.

As shown in Table 2, there was no difference in the successful reperfusion rate (mTICI $2 \mathrm{~b} / 3$ ) between the study groups, with a fully adjusted OR associated with the Neck-First group of 1.18 (95\% confidence interval [CI], 0.60-2.17). Figure 2 shows the distributions of reperfusion rates according to the study groups. Among patients with successful reperfusion, the time to achieve successful reperfusion from groin puncture was significantly shorter in the Head-First group even after adjustment for baseline between-group differences (56 min [39-90] vs. 70 min [50-102], fully adjusted $p=0.001$ ). Regarding secondary outcomes, we found a higher rate of complete reperfusion (mTICI 3) in the Neck-First group compared to the Head-First group (41.2 vs. $25.3 \%$, center-adjusted $p=0.017$ ); however, this difference was not significant in the fully adjusted analysis (OR, 1.68; 95\% CI, 0.96-2.93; $p=0.068$ ). We found no significant differences in other secondary outcomes (Table 2); only a nonsignificant higher risk of parenchymal hematoma in the Neck-First group compared to the Head-First group was observed (fully adjusted OR, 2.28; 95\% CI, 0.94-5.51; $p=0.068$ ) with no differences in the rates of symptomatic ICH (fully adjusted OR, $2.41 ; 95 \% \mathrm{CI}, 0.61-9.47 ; p=0.21$ ).

Sensitivity analysis excluding patients with complete occlusion of the cervical carotid artery yielded similar results with no difference in successful reperfusion (mTICI $2 b / 3$ ), faster interval between puncture to successful reperfusion in the Head-First group in the fully adjusted analysis. The only exception is that the difference in the parenchymal hematoma rate was more pronounced and became significantly more common in the Neck-First arm (fully adjusted OR, 10.05, 95\% CI, 1.99-50.68; $p=0.005$ ) (Table 3).

\section{Discussion}

We demonstrate that the Head-First and Neck-First approaches lead to a similar rate of successful reperfusion, while targeting the head upfront was associated with faster times from puncture to reperfusion in a large multicenter cohort.

Tandem occlusions constituted a significant portion (17-32\%) of the cases included in recent thrombectomy trials $[4,11,12]$. The treatment effect of thrombectomy in patients with tandem occlusions has been demonstrated to be comparable to the treatment of isolated intracranial occlusions [1]. However, refinement in the technical aspects of tandem occlusion patients is important. One of the unproven and critical questions is which lesion should be approached first: the intracranial lesion or the cervical lesion. The available data exploring 


\section{Interventional Neurology}

\begin{tabular}{l|l}
\hline Intervent Neurol 2019;8:92-100 \\
\hline DOI: 10.1159/000496292 & $\begin{array}{l}\text { @ 2019 S. Karger AG, Basel } \\
\text { www.karger.com/ine }\end{array}$ \\
\hline
\end{tabular}

Haussen et al.: Head or Neck First? Speed and Rates of Reperfusion in Thrombectomy for Tandem Large Vessel Occlusion Strokes

Table 1. Baseline and procedural characteristics

\begin{tabular}{|c|c|c|c|c|c|}
\hline & \multirow[t]{2}{*}{ Overall } & \multicolumn{2}{|c|}{ Endovascular treatment } & \multirow[t]{2}{*}{$p$ value } & \multirow[t]{2}{*}{ ASD, \% } \\
\hline & & Head-First & Neck-First & & \\
\hline Patients, $n$ & 289 & 107 & 182 & & \\
\hline Mean age $\pm S D$, years & $66.7(10.5)$ & $65.9(10.5)$ & $67.2(10.5)$ & 0.33 & 12.0 \\
\hline Males & $187 / 288(64.9)$ & $68 / 106(64.2)$ & $119 / 182(65.4)$ & 0.83 & 2.6 \\
\hline \multicolumn{6}{|l|}{ Medical history } \\
\hline Hypertension & $168 / 266(63.2)$ & $55 / 93(59.1)$ & $113 / 173(65.3)$ & 0.32 & 12.8 \\
\hline Diabetes & $45 / 267(16.9)$ & $18 / 94(19.2)$ & $27 / 173(15.6)$ & 0.46 & 9.4 \\
\hline Hypercholesterolemia & $112 / 267(42.0)$ & $33 / 94(35.1)$ & $79 / 173(45.7)$ & 0.09 & 21.6 \\
\hline Current smoking & $82 / 258(31.8)$ & $25 / 92(27.2)$ & $57 / 166(34.3)$ & 0.24 & 15.6 \\
\hline Mean admission NIHSS score \pm SD $^{a}$ & $15.7(6.0)$ & $15.8(6.2)$ & $15.7(5.9)$ & 0.90 & 1.5 \\
\hline Median ASPECTS (IQR) ${ }^{\mathrm{b}}$ & $8(7-9)$ & $7(6-8)$ & $8(7-10)$ & $<0.001$ & 47.6 \\
\hline \multicolumn{6}{|l|}{ Cervical ICA lesion } \\
\hline Stenosis $\geq 90 \%$ & $163 / 289(56.4)$ & $46 / 107(43.0)$ & $117 / 182(64.7)$ & $<0.001$ & 43.7 \\
\hline Complete occlusion & $126 / 289(43.6)$ & $61 / 107(57.0)$ & $65 / 182(35.7)$ & & \\
\hline \multicolumn{6}{|l|}{ Intracranial occlusion location } \\
\hline MCA & $198 / 289(68.5)$ & $77 / 107(72.0)$ & $121 / 182(66.5)$ & 0.33 & 11.9 \\
\hline ICA & $91 / 289(31.5)$ & $30 / 107(28.0)$ & $61 / 182(33.5)$ & & \\
\hline \multicolumn{6}{|l|}{ Treatment details } \\
\hline IV thrombolysis & $175 / 289(60.6)$ & $63 / 107$ (58.9) & $112 / 182(61.5)$ & 0.66 & 5.4 \\
\hline General anesthesia & $164 / 289(56.8)$ & $59 / 107(55.1)$ & $105 / 182(57.7)$ & 0.67 & 5.2 \\
\hline Median onset to groin puncture (IQR), $\mathrm{min}^{\mathrm{c}}$ & $250(180-333)$ & $259(180-345)$ & $247(180-322)$ & 0.64 & 7.0 \\
\hline \multicolumn{6}{|l|}{ Thrombectomy device } \\
\hline Stent retriever & $255 / 289(88.2)$ & 96/107 (89.7) & $159 / 182(87.4)$ & 0.55 & 7.4 \\
\hline Contact aspiration & $34 / 289(11.8)$ & $11 / 107(10.3)$ & $23 / 182(12.6)$ & & \\
\hline
\end{tabular}

Values are expressed as $n /$ total $n(\%)$, unless otherwise indicated. Bold values indicate significance. ASD, absolute standardized difference; ASPECTS, Alberta Stroke Program Early CT Score; CT, computed tomography; ICA, internal carotid artery; IQR, interquartile range; IV, intravenous; MCA, middle cerebral artery; NIHSS, National Institutes of Health Stroke Scale; $\mathrm{SD}$, standard deviation. ${ }^{\mathrm{a}} 1$ missing value; ${ }^{\mathrm{b}} 27$ missing values; ${ }^{\mathrm{c}} 98$ missing values.

Table 2. Procedural and clinical outcomes according to the treatment groups

\begin{tabular}{|c|c|c|c|c|c|c|}
\hline \multirow[t]{2}{*}{ Outcomes } & \multicolumn{2}{|c|}{ Endovascular treatment } & \multicolumn{2}{|l|}{ Center adjusted } & \multicolumn{2}{|l|}{ Fully adjusted ${ }^{\mathrm{c}}$} \\
\hline & Head-First & Neck-First & OR $(95 \% \mathrm{CI})$ & $p$ value & OR $(95 \% \mathrm{CI})$ & $p$ value \\
\hline mTICI $2 \mathrm{~b} / 3$ (successful reperfusion) & $79 / 107$ (73.8) & $145 / 182(79.7)$ & $1.31(0.69-2.46)$ & 0.40 & $1.18(0.60-2.17)$ & 0.68 \\
\hline mTICI 3 (complete reperfusion) & $27 / 107(25.3)$ & $75 / 182(41.2)$ & $1.95(1.12-3.38)$ & 0.017 & $1.68(0.96-2.92)$ & 0.068 \\
\hline Median puncture to successful reperfusion time (IQR), min & $56(39-90)$ & $70(50-102)$ & n.a. & $0.011^{\mathrm{a}}$ & n.a. & 0.001 \\
\hline 90-day mRS score $0-2$ & $51 / 104(49.0)$ & $96 / 181(53.0)$ & $1.17(0.71-1.91)$ & 0.52 & $1.15(0.68-1.93)$ & 0.59 \\
\hline Any procedural complication(s) ${ }^{\mathrm{b}}$ & $19 / 102(18.6)$ & $21 / 178$ (11.8) & $0.70(0.32-1.51)$ & 0.36 & $0.77(0.34-1.67)$ & 0.49 \\
\hline 90-day mortality & $18 / 104(17.3)$ & $26 / 181(14.4)$ & $0.80(0.41-1.55)$ & 0.51 & $0.99(0.49-1.99)$ & 0.97 \\
\hline Any ICH & $43 / 107$ (40.2) & $75 / 160(46.9)$ & $1.02(0.59-1.76)$ & 0.95 & $1.05(0.61-1.82)$ & 0.85 \\
\hline Parenchymal hematoma type $1 / 2$ & $11 / 107$ (10.3) & $27 / 160(16.9)$ & $1.78(0.79-3.99)$ & 0.16 & $2.28(0.94-5.51)$ & 0.068 \\
\hline Symptomatic ICH & $4 / 107$ (3.7) & $11 / 150(6.9)$ & $1.89(0.53-6.78)$ & 0.33 & $2.41(0.61-9.47)$ & 0.21 \\
\hline
\end{tabular}

Values are expressed as $n /$ total $n(\%)$, unless otherwise indicated. ORs were calculated using Head-First as the reference group. Bold values indicate significance. $\mathrm{CI}$, confidence interval; mTICI, modified Thrombolysis in Cerebral Infarction; mRS, modified Rankin Scale; OR, odds ratio; ICH, intracerebral hemorrhage. ${ }^{a}$ Calculated on log-transformed value. ${ }^{b}$ Embolic new territory $(n=28)$, vessel perforation $(n=4)$, carotid dissections $(n=3)$, and other complications $(n=5)$. ${ }^{\mathrm{c}}$ Adjusted for center and baseline between-group differences (i.e., hypercholesterolemia, Alberta Stroke Program Early CT Score, and cervical internal carotid artery lesion [stenosis $\geq 90 \%$ vs. occlusion]) and calculated after handling missing data by multiple imputation $(m=10)$. 


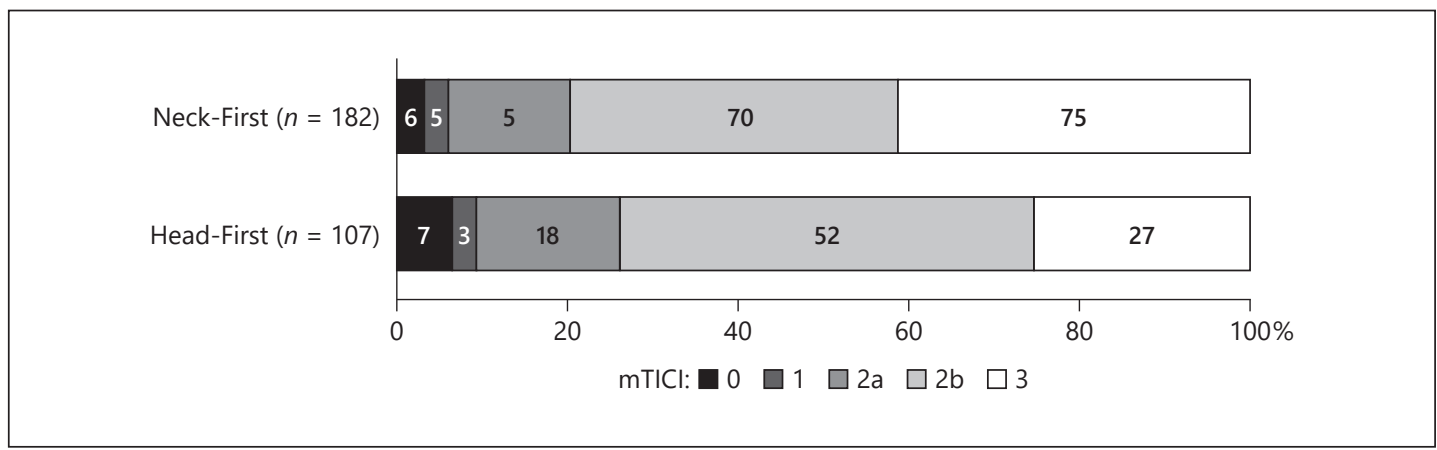

Fig. 2. Reperfusion rates according to the treatment group.

the order of treatment is very limited. One study compared 7 patients with the Head-First approach with 38 patients with Neck-First, and there was no observed statistical difference in the time to reperfusion, reperfusion rates, or clinical outcomes between the groups [6]. Another study compared 12 Neck-First against 25 Head-First cases and demonstrated a faster time to reperfusion in the Head-First approach, with similar safety and clinical outcomes between the arms [5]. Sample sizes were small, and populations were heterogeneous, with the inclusion of dissection-related occlusions in addition to atherosclerotic cervical lesions. A meta-analysis observed no differences in reperfusion rates and clinical outcomes between the groups [13]. However, the methodology did not allow for adjustments for expected baseline clinical imbalances. A recent study demonstrated that 59 patients who received thrombectomy followed by neck revascularization had better reperfusion rates and rates of independence at 90 days compared to matched with 41 individuals who underwent neck revascularization followed by thrombectomy. Unfortunately, the authors did not adjust for baseline ischemic core size. Recently, a matched analysis of 100 patients demonstrated improved reperfusion rates and clinical outcomes in patients treated with the Head-First as compared to the Neck-Frist approach [14].

We observed that the Head-First approach lead to faster reperfusion with no impact on the overall rates of reperfusion. We believe that there are two separate issues that are independently important but inherently interconnected in clinical practice: (1) the order of the approach, and (2) the decision for definitive revascularization (stent or angioplasty). Our findings support the theory that many operators aim for the intracranial occlusion upfront when the core is larger. This allows faster intracranial reperfusion, which is particularly important in cases of poor leptomeningeal collateral circulation. Moreover, it does not necessarily commit such patients to the risks of cervical revascularization in individuals with larger ischemic cores. This approach avoids abrupt increases in perfusion pressures that would occur if the cervical stent deployed in patients with chronically exhausted vasomotor reactivity related to steno-occlusive carotid disease, circumvents the need for dual antithrombotic therapy, and therefore may minimize the risk of parenchymal hematomas as observed in our study. Considering the differences in baseline ischemic core burden and the fact that fewer patients underwent cervical carotid revascularization in the Head-First group, clinical outcomes are less appropriate for comparisons. The potential benefits of the observed faster reperfusion in the Head-First could have been offset by the more severe strokes (lower ASPECTS scores) at baseline. The rates of reperfusion and time to reperfusion may be less dependent on the clinical effects of carotid stent revascularization and were therefore used as primary outcome measures. 
Table 3. Sensitivity analysis excluding patients with complete cervical carotid occlusion

\begin{tabular}{|c|c|c|c|c|c|c|}
\hline \multirow[t]{2}{*}{ Outcomes } & \multicolumn{2}{|c|}{ Endovascular treatment } & \multicolumn{2}{|l|}{ Center adjusted } & \multicolumn{2}{|l|}{ Fully adjusted $^{\mathrm{c}}$} \\
\hline & Head-First & Neck-First & OR $(95 \% \mathrm{CI})$ & $p$ value & OR $(95 \% \mathrm{CI})$ & $p$ value \\
\hline mTICI $2 \mathrm{~b} / 3$ (successful reperfusion) & $35 / 46(76.1)$ & $99 / 117(84.6)$ & $1.46(0.59-3.63)$ & 0.41 & $1.23(0.48-3.15)$ & 0.66 \\
\hline mTICI 3 (complete reperfusion) & $13 / 46(28.3)$ & $54 / 117(46.2)$ & $2.18(1.03-4.58)$ & 0.041 & $1.88(0.86-3.98)$ & 0.11 \\
\hline $\begin{array}{l}\text { Median puncture to successful reperfusion } \\
\text { time (IQR), min }\end{array}$ & $55(31-93)$ & $71(54-112)$ & n.a. & $0.030^{\mathrm{a}}$ & n.a. & 0.005 \\
\hline 90-day mRS score $0-2$ & $21 / 46(45.7)$ & $63 / 117(53.9)$ & $1.29(0.63-2.63)$ & 0.48 & $1.09(0.51-2.29)$ & 0.82 \\
\hline Any procedural complication $(\mathrm{s})^{\mathrm{b}}$ & $8 / 43(18.6)$ & $11 / 116(9.5)$ & $0.65(0.21-1.97)$ & 0.45 & $0.77(0.24-2.47)$ & 0.67 \\
\hline 90-day mortality & $9 / 46(19.6)$ & $16 / 117(13.7)$ & $0.65(0.26-1.61)$ & 0.35 & $0.90(0.34-2.36)$ & 0.83 \\
\hline Any ICH & $22 / 46(47.8)$ & $56 / 107(52.3)$ & $1.05(0.51-2.18)$ & 0.89 & $1.13(0.54-2.35)$ & 0.75 \\
\hline Parenchymal hematoma type $1 / 2$ & $2 / 46(4.4)$ & $22 / 107(20.6)$ & $5.69(1.26-25.66)$ & 0.024 & $10.05(1.99-50.68)$ & 0.005 \\
\hline Symptomatic ICH & $1 / 46(2.2)$ & 9/107 (8.4) & $3.85(0.45-32.86)$ & 0.22 & $5.88(0.62-55.57)$ & 0.12 \\
\hline
\end{tabular}

Values expressed as $n /$ total $n(\%)$, unless otherwise as indicated. Bold values indicate significance. CI, confidence interval; mTICI, modified Thrombolysis in

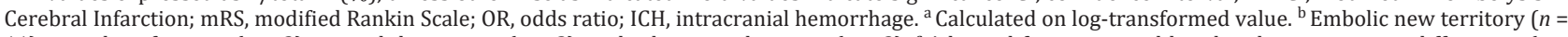
11 ), vessel perforation $(n=3)$, carotid dissections $(n=2)$, and other complications $(n=3)$. ${ }^{c}$ Adjusted for center and baseline between-group differences (i.e., hypercholesterolemia and Alberta Stroke Program Early CT Score) and calculated after handling missing data by multiple imputation ( $m=10$ ).

The presence of complete cervical carotid occlusion (more common in the Head-First patients) is theoretically associated with a larger thrombus load and more challenging intracranial access as compared to patients with high-grade stenosis. Despite the higher frequency of complete occlusion, the Head-First approach lead to similar rates of successful reperfusion. When excluding patients with complete occlusion, the rates of complete reperfusion (indirect measure of absence of emboli to new or same territory) were not statistically different in the fully adjusted analysis (although in center-adjusted analysis, it was more common in HeadFirst patients).

The strengths of the present study include the multicenter design, the sample size, and the homogeneous cohort of patients with atherosclerotic tandem etiology. However, the present findings are derived from observational analyses, which are subject to well-known limitations. The first is the potential for confounding by measured or unmeasured variables, which cannot be ruled out, even after adjustment for meaningful between-group differences. A second limitation is the presence of missing data in some covariates. Although we used multiple imputations to handle missing data as appropriate, we could not exclude that missing data could introduce a bias in estimates. Since no formal sample size calculation was done, we cannot exclude that some differences were overlooked due to the lack of adequate statistical power. In a post hoc power assessment, we calculated the smallest significant betweengroup difference (expressed as OR) that our study sample size allowed us to detect with an $80 \%$ power. Assuming an incidence of outcome of 10 and $50 \%$ in the reference group, we could respectively detect an OR of 2.65 and 2.02 (or 0.20 and 0.50 for the protective effect). We also caution that we could not exclude false-positive findings regarding multiple comparisons. We have not adjusted for different techniques used with stent retriever as well as with thromboaspiration (and combinations), which could have influenced the study results. We have not collected information regarding recurrent strokes and staged revascularization in patients not emergently stented. Finally, we have not evaluated the frequency of intracerebral occlusion recanalization after the proximal occlusion, which could be another advantage of the Neck-First approach. For all these reasons, further studies are warranted to confirm our findings. 


\section{Conclusion}

The upfront approach of the intracranial lesion in patients with tandem large vessel occlusion strokes of the anterior circulation leads to similar reperfusion rates but faster reperfusion as compared to initial cervical revascularization followed by thrombectomy. Controlled studies are warranted.

\section{Appendix}

TITAN (Thrombectomy In TANdem Lesions) Investigators

Andreas Kastrup, Adrien Guenego, Julien Darcourt, Isabelle Vukasinovic, Elisa Pomero, Jason Davies, Leonardo Renieri, Corentin Hecker, Maria Muchada, Arturo Consoli, Georges Rodesch, Emmanuel Houdart, Raymond Turner, Aquilla Turk, Imran Chaudry, Johanna Lockau, Raphaël Blanc, Hocine Redjem, Daniel Behme, Hussain Shallwani, Maurer Christopher, Gioia Mione, Lisa Humbertjean, Jean Christophe Lacour, Anne-Laure Derelle, Romain Tonnelet, Liang Liao.

\section{Statement of Ethics}

All local institutional review boards approved the study.

\section{Disclosure Statement}

D.C.H.; F.T.; M.P.; J.L.; H.S.-A.; M.H.; C.T.; S.E.; P.P.; M.B.; A.H.S.; B.L.; F.D.; C.C.; M.K.; S.M.; M.R.; M.N.P.; A.M.S.; M.-A.L.; M.M.; A.B.; S.R.; J.A.G.; R.A.; S.B.; B.G. have nothing to disclose. R.G.N.: Stryker-Neurovacular (Trevo-2\&DAWN/Trial PI), Covidien (SWIFT\&SWIFT-PRIME/Steering-Committee, STAR Trial/Core-Lab), Penumbra (3-D Separator Trial/Executive-Committee).

\section{Funding Sources}

Institutional grant - Stryker to University Hospital of Nancy, and University of Lorraine, France.

\section{Author Contributions}

D.C.H.: Study conception, design of the work, acquisition of data, statistical analysis, interpretation of data, drafting of the manuscript.

J.L.: Design of the work, statistical analysis, interpretation of data.

F.T.; M.P.; H.S.-A.; M.H.; C.T.; S.E.; R.G.N.; P.P.; M.B.; A.H.S.; B.L; F.D.; C.C.; M.K.; S.M.; M.R.; M.N.P.; A.M.S.; M.-A.L.; M.M.; A.B.; S.R.; J.A.G.; R.A.; S.B.; B.G.: Data acquisition, critical revision of manuscript.

B.G.: Acquisition of the data, interpretation of the data, critical revision of the manuscript.

All authors gave final approval of the version to be published and agree to be accountable for all aspects of the work in ensuring that questions related to the accuracy or integrity of any part of the work are appropriately investigated and resolved.

\section{References}

1 Goyal M, Menon BK, van Zwam WH, Dippel DW, Mitchell PJ, Demchuk AM, et al.; HERMES collaborators. Endovascular thrombectomy after large-vessel ischaemic stroke: a meta-analysis of individual patient data from five randomised trials. Lancet. 2016 Apr;387(10029):1723-31.

2 Goyal M, Demchuk AM, Menon BK, Eesa M, Rempel JL, Thornton J, et al.; ESCAPE Trial Investigators. Randomized assessment of rapid endovascular treatment of ischemic stroke. N Engl J Med. 2015 Mar;372(11):1019-30. 
3 Jovin TG, Chamorro A, Cobo E, de Miquel MA, Molina CA, Rovira A, et al.; REVASCAT Trial Investigators. Thrombectomy within 8 hours after symptom onset in ischemic stroke. N Engl J Med. 2015 Jun;372(24):2296-306.

4 Berkhemer OA, Fransen PS, Beumer D, van den Berg LA, Lingsma HF, Yoo AJ, et al.; MR CLEAN Investigators. A randomized trial of intraarterial treatment for acute ischemic stroke. N Engl J Med. 2015 Jan;372(1):11-20.

5 Lockau H, Liebig T, Henning T, Neuschmelting V, Stetefeld H, Kabbasch C, et al. Mechanical thrombectomy in tandem occlusion: procedural considerations and clinical results. Neuroradiology. 2015 Jun;57(6):589-98.

6 Rangel-Castilla L, Rajah GB, Shakir HJ, Shallwani H, Gandhi S, Davies JM, et al. Management of acute ischemic stroke due to tandem occlusion: should endovascular recanalization of the extracranial or intracranial occlusive lesion be done first? Neurosurg Focus. 2017 Apr;42(4):E16.

7 Gory B, Haussen DC, Piotin M, Steglich-Arnholm H, Holtmannspotter M, Labreuche J, Kyheng M, Taschner C, Eiden S, Nogueira RG, Papanagiotou P, Boutchakova M, Siddiqui AH, Lapergue B, Dorn F, Cognard C, Killer M, Mangiafico S, Ribo M, Psychogios MN, Spiotta AM, Labeyrie MA, Biondi A, Mazighi M, Turjman F, Thrombectomy In TLI: Impact of Intravenous Thrombolysis and Emergent Carotid Stenting on Reperfusion and Clinical Outcomes in Acute Stroke Patients with Tandem Lesion treated with Thrombectomy: A Collaborative Pooled Analysis. European journal of neurology : the official journal of the European Federation of Neurological Societies. Mar 25 2018. https://doi.org/10.1111/ene.13633.

8 Gory B, Piotin M, Haussen DC, Steglich-Arnholm H, Holtmannspötter M, Labreuche J, et al.; TITAN Investigators. Thrombectomy in Acute Stroke With Tandem Occlusions From Dissection Versus Atherosclerotic Cause. Stroke. 2017 Nov;48(11):3145-8.

9 Buuren SG, Groothuis-Oudshoorn K. mice: multivariate imputation by chained equations in R. Journal of statistical software. J Stat Softw. 2011;45(3). https://doi.org/10.18637/jss.v045.i03.

10 D R. Multivariate Imputation for Nonresponse in Surveys. New York: J. Wiley \& Sons; 1987.

11 Liebeskind DS, Jahan R, Nogueira RG, Jovin TG, Lutsep HL, Saver JL, et al. Early arrival at the emergency department is associated with better collaterals, smaller established infarcts and better clinical outcomes with endovascular stroke therapy: SWIFT study. J Neurointerv Surg. 2015;(May):11.

12 Goyal M, Demchuk AM, Menon BK, Eesa M, Rempel JL, Thornton J, et al. the ETI: Randomized Assessment of Rapid Endovascular Treatment of Ischemic Stroke. N Engl J Med. 2015;(Feb):11.

13 Wilson MP, Murad MH, Krings T, Pereira VM, O'Kelly C, Rempel J, et al. Management of tandem occlusions in acute ischemic stroke - intracranial versus extracranial first and extracranial stenting versus angioplasty alone: a systematic review and meta-analysis. J Neurointerv Surg. 2018 Aug;10(8):721-8.

14 Maus V, Borggrefe J, Behme D, Kabbasch C, Abdullayev N, Barnikol UB, et al. Order of Treatment Matters in Ischemic Stroke: Mechanical Thrombectomy First, Then Carotid Artery Stenting for Tandem Lesions of the Anterior Circulation. Cerebrovasc Dis. 2018;46(1-2):59-65. 